\title{
Molecular Characterization and Genetic Diversity of Clade E-Human Head Lice from Guinea
}

Alissa Hammoud ${ }^{1}$, Meriem Louni ${ }^{2,3 *}$, Mamadou Cellou Baldé ${ }^{4}$, Abdoul Habib Beavogui ${ }^{5,6}$, Philippe Gautret $^{2}$, Didier Raoult ${ }^{1}$, Florence Fenollar ${ }^{2}$, Dorothée Misse $^{7}$, Oleg Mediannikov ${ }^{1 *}$

${ }^{1}$ Aix Marseille Univ, IRD, APHM, MEPHI, IHU-Méditerranée Infection, Marseille, France.

${ }^{2}$ Aix Marseille Univ, IRD, APHM, VITROME, IHU-Méditerranée Infection, Marseille, France.

${ }^{3}$ Faculté des Sciences, Université M'Hamed Bougara Boumerdes, Boumerdès, Algérie.

${ }^{4}$ Institut de Recherche en Biologie Appliquée de Guinée (IRBAG), Kindia, Guinée

${ }^{5}$ Centre de Formation et de Recherche en Santé Rurale de Mafèrinyah B.P. 2649, Conakry, Guinée.

${ }^{6}$ Faculté de Médecine, Pharmacie et Odontostomatologie, Université Gamal Abdel Nasser de Conakry, Guinée.

${ }^{7}$ Maladies Infectieuses Et Vecteurs : Écologie, Génétique, Evolution Et Contrôle, MIVEGEC UMR 224, Univ Montpellier, IRD, CNRS, Montpellier, France

*Correspondence: louni_meriem@yahoo.fr and olegusss1@gmail.com 


\begin{abstract}
Pediculus humanus capitis, the head louse, is an obligate blood-sucking ectoparasite that occurs in six divergent mitochondrial haplogroups (A, D, B, F, C and E), each exhibiting a particular geographic distribution. A few years ago, several studies reported the presence of different pathogenic agents in head lice specimens from different clades collected worldwide. These findings suggest that head louse could be a vector for dangerous diseases and therefore a serious public health problem. Herein, we aimed to study the mitochondrial genetic diversity, the PHUM540560 gene polymorphisms profile of head lice collected in Guinea, as well as to screen for the pathogens present in these lice.

In 2018, a total of 155 head lice were collected from 49 individuals at the Medicals Centers of rural (Maférinyah village) and urban (Kindia city) areas, in Guinea. All head lice were subjected to genetic analysis and screened for the presence of several pathogens using molecular tools. The results showed that all head lice belonged to the haplogroups $\mathrm{C} / \mathrm{E}$ using the duplex qPCR which detects both clades. Standard PCR and sequencing revealed that all specimens belonged to the haplogroup E, including 8 haplotypes, whither 6 new identified for the first time in this study. The study of the PHUM540560 gene polymorphisms in our Guinean head lice revealed that 7/40 (17.5\%) of our tested samples exhibit three different polymorphism profiles compared to the clade A-head lice PHUM540560 gene profile, while the remaining specimens 33/40 (82,5\%) showed the same PHUM540560 gene polymorphism profile as the previously reported clade A-body lice. Molecular investigations of the targeted pathogens revealed only the presence of Acinetobacter species in $9 \%$ of our samples using real time PCR. Sequencing results identified highlighted the presence of several Acinetobacter species, including Acinetobacter baumannii (14.3\%), Acinetobacter nosocomialis (14.3\%), Acinetobacter variabilis (14.3\%), Acinetobacter
\end{abstract}


haemolyticus (7.2\%), Acinetobacter towneri (7.2\%). Furthermore, a candidate new species of Acinetobacter sp. (7.2\%) was detected. Positive specimens were collected from 24,5\% individuals in Maférinyah. We also investigated in our study the carbapenem's-resistant profile of $A$. baumannii, none of our specimens were positive for the following resistance genes bla $_{\text {OXA-21 }}$, bla $_{\text {OXA-24 }}$ and bla OXA-58.

To the best of our knowledge, our study is the first to report the existence of the Guinean haplogroup E, the PHUM540560 gene polymorphism profile as well as the presence of Acinetobacter species in head lice collected from Guinea.

Keywords: Head lice, haplogroup E, PHUM540560 gene, Acinetobacter haemolyticus, Acinetobacter spp., Guinea. 


\section{Introduction}

Sucking lice (Phthiraptera: Anoplura) are obligate ectoparasites that have co-speciated with their hosts for at least 77 million years [1]. Humans are colonized by two genera of lice, Pediculus and Phtirus, that have been strictly feeding on human blood for nearly 5.6 million years [2]. Pediculus genus includes: human (Homo sapiens) lice, Pediculus humanus; chimpanzees (Pan troglodytes) lice P. schaeffi; and New World monkeys (Platyrrhini) lice, $P$. mjobergi [3]. While Phtirus genus includes Phtirus pubis, parasite of humans and Pt. gorilla, parasite of gorillas (Gorilla) [2,4]. The Pediculus humanus includes two ecotypes and is a great public health concern: the Pediculus humanus humanus (body louse), which lives in clothing and infests people living in poverty and lack of hygiene. Pediculus humanus capitis (head louse), lives in the scalp area, with a worldwide distribution regardless of hygienic conditions [5]. Aside from their role as pests, human lice can be a significant health hazard [3]. Indeed, body lice are the main vector of various serious human pathogens, including Rickettsia prowazekii, Bartonella quintana, Borrelia recurrentis and probably Yersinia pestis. These agents respectively cause epidemic typhus, trench fever, relapsing fever and plague $[3,6]$. Although it is assumed that body lice are a more potent vector for pathogens, the role of head lice as pathogens-vector is still debated and misunderstood [7]. This can be explained by the fact that head lice proceed to a rapid elimination of ingested bacteria, caused by a stronger immune response and therefore a weaker vectorial capacity compared to body lice $[8,9]$. However, under experimental conditions, the acquisition and the maintenance of $R$. prowazekii and B. quintana are reported in head lice $[7,10]$. Moreover, epidemiological studies have strongly implicated head lice as a vector of infectious pathogens under favorable epidemiological conditions [11]. Various studies have reported that head lice collected worldwide show the presence of DNA from several pathogenic 
bacteria including : B. quintana, B. recurrentis, Borrelia theileri, Y. pestis, Coxiella burnetii, Rickettsia aeschlimannii, Acinetobacter spp., as well as potential new species of the genera Moraxella, Psychrobacter, Ehrlichia and Anaplasma [12-30]. These data highlight the fact that head lice can harbor pathogenic bacteria and probably even transmit them to their human hosts. It is therefore obvious that it is important to prevent potential epidemics related to these ectoparasites.

Robust phylogenetic studies of human lice based on mitochondrial DNA, mainly cytochrome $b[c y t b]$ and cytochrome oxidase subunit $1[$ coxl] genes, have inferred Pediculus humanus into six divergent mitochondrial clades (haplogroups): A, D, C, E, B and F, each with distinct geographical distribution [5,14,31-33]. Human lice also present an intra-clade diversity in addition to their inter-clade diversity, which is illustrated by several distinct haplotypes for each haplogroup $[21,31,34]$. Unlike body lice, which only belong to clades A and D, head lice encompass all the genetic diverse clades [18]. Clade A has a global continental distribution and it is the most prevalent [31,34], while clade D is restricted to sub-Saharan African countries, and has so far been reported in the Democratic Republic of Congo (DRC), the Republic of Congo (Congo-Brazzaville), Ethiopia and Zimbabwe [14,21,31]. Clade C has been identified mainly in African and Asian countries, including Ethiopia, Republic of Congo, Nepal, Pakistan and Thailand $[18,21,24]$. The sister group of clade $\mathrm{C}$, the clade $\mathrm{E}$, has specific distribution to West Africa where it has been reported with high prevalence of lice in Senegal, Mali [18], Nigerian migrants' refugees' communities in Algeria [26] and from migrant communities living in Bobigny, France [25]. Recently, two studies reported for the first time the presence of clade E in Central Africa. A new haplotype that has never been described in clade $\mathrm{E}$ has been isolated in Congo. While the Malian clade E haplotype, was highly detected in head lice from Gabon [28, 
29]. Clade B is found in a high diversification in America, it has been reported in Western Europe, Australia, North Algeria, South Africa, Saudi Arabia, and is also present among the remains of head lice from the Roman period dating back to about 2000 years [31,34-37]. Recently, a novel clade F, the sister group of clade B, was described in French Guiana, in head lice recovered from the Wayampi community living in a remote Trois-Sauts village. This clade was also found in Argentina and Mexico [33]. All these data confirm important facts about the evolutionary history of lice, as well as the ancestors of their human hosts since their migration out of Africa [38].

Despite their clade diversification and ecological niches, The Pediculus humanus ecotypes are morphologically and biologically almost similar [3,5]. Previous genetic studies targeting intergenic spacers, using a highly polymorphic markers were not able to differentiate between body and head lice $[38,39]$. Moreover, a study based on the comparison of head and body lice transcriptomes, reported that the two ecotypes had a single 752-base pair (bp) difference in the Phum_PHUM540560 gene, with differential expression that encodes a hypothetical 69-amino acids protein of unknown function [40]. The PHUM540560 gene and 13 others were thought to be missing in head louse. However, a study conducted by Drali and collaborators, showed that the head louse also harbors this gene, but with a rearranged sequence compared to body louse. The variation of the Phum_PHUM540560 gene within the two ecotypes allowed the design and development of a novel molecular tool based on multiplex real-time PCR assays, in order to differentiate the Clade A body and head lice [41].

In Guinea, West Africa, human lice infestation is very frequent but never investigated. In this study, we aimed to identify for the first time in Guinea, the genetic diversity status of head lice collected from two sites: rural (Maférinyah village) and urban (Kindia city), the 
Phum_PHUM540560 gene polymorphisms, as well as to assess the occurrence of bacterial pathogens in these lice.

\section{Materials and Methods}

\subsection{Lice collection and DNA extraction}

In December 2018, head lice collection was carried out at Medical Centers in two areas: Maférinyah $\left(9.5466^{\circ} \mathrm{N}, 13.2866^{\circ} \mathrm{W}\right)$ and Kindia $\left(10.0407^{\circ} \mathrm{N}, 12.8630^{\circ} \mathrm{W}\right)$ from Guinea in West Africa (Fig.1). All individuals in medical centers with a head lice infestation were asked to perform a complete self-examination for the presence of head and body lice. The medical center personnel obtained verbal consent from the participants and authorization from the head of the medical center to supervise the collection process.

A total of 155 head lice were obtained from 49 individuals (Mean age: 11 [2, 62], 96\% female): 130 head lice specimens were collected from 38 individuals in Maférinyah (Mean age: $10[2,35], 100 \%$ female), and 25 head lice samples were collected from 11 individuals (Mean age: 16,2 [6, 62]; $81.9 \%$ female) in Kindia. No body lice were found during the examination. The collected head lice were stored in dry sterile conditions at room temperature and then transported to the laboratory of IHU- Méditerranée Infection, Marseille, France and stored at $20^{\circ} \mathrm{C}$ until molecular study.

In order to decontaminate the external surface and avoid bacterial contamination, each louse specimen was washed and decontaminated as previously described [42]. Dried louse specimen was cut in half lengthwise, the first half was frozen at $-20{ }^{\circ} \mathrm{C}$ for subsequent studies. Total DNA was extracted from the remaining half using a DNA extraction kit, QIAamp Tissue Kit (Qiagen, Courtaboeuf, France) in the EZ1 apparatus following the manufacturer's instructions. 


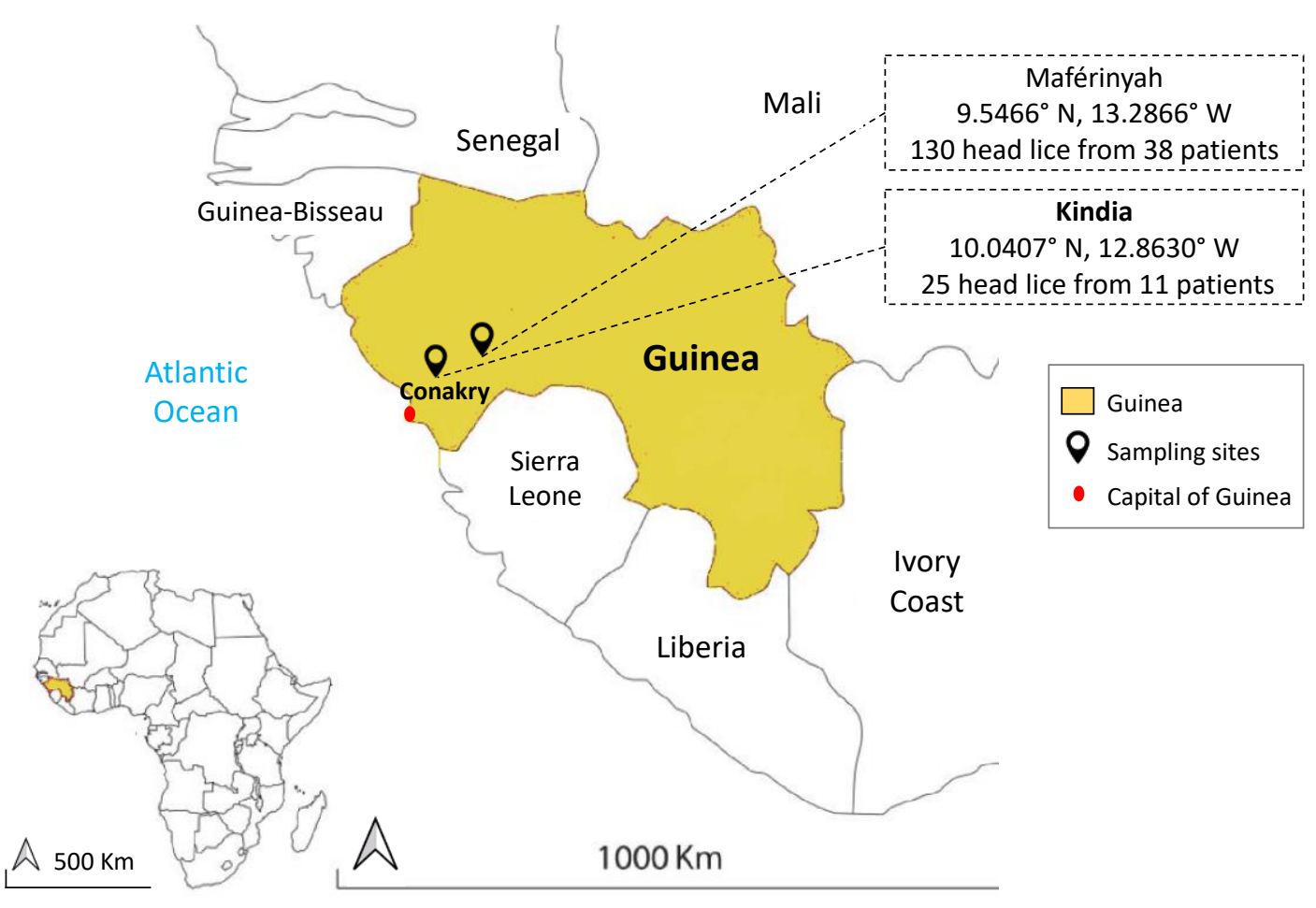

Figure 1. Map of head lice collection sites from infested individuals in two localities in Guinea.

\subsection{Genotypic status of lice}

2.2.1. Identification of louse mitochondrial haplogroup by qPCR assays

In order to identify the mitochondrial clades of the lice collected in this study, all DNA samples were analyzed by clade-specific quantitative duplex real time PCR (qPCR) assays targeting a portion of the $c y t b$ gene. Each duplex is specific to clades A-D and B-C as previously described, noting that the B-C duplex amplifies specimens belonging to clade $\mathrm{E}$, classified as a sub-clade within clade C $[18,21]$. Clades PCR identification was carried out using a CFX96 Real- Time system (Bio-Rad Laboratories, Foster City, CA, USA). The amplification of DNA was performed using the following parameters: one step of incubation at $50{ }^{\circ} \mathrm{C}$ for $2 \mathrm{~min}$ (for UDG activation), one step of $95^{\circ} \mathrm{C}$ for 5 min for initial denaturation and 45 cycles of 5 seconds 
at $95^{\circ} \mathrm{C}$ and 30 seconds at $60^{\circ} \mathrm{C}$. The final reaction volume of $20 \mu 1$ contained $10 \mu 1$ of Eurogentec $^{\mathrm{TM}}$ Probe PCR Master Mix (Eurogentec, Liege, Belgium), $0.5 \mu \mathrm{M}$ of each primer, probe and water. To validate the qPCR run, lice with known clades were used as positive controls and master mixtures as negative controls for each test.

2.2.2. Identification of louse haplotype by conventional PCR assays and sequencing

In order to perform a phylogenetic study, all head lice specimens were subjected to standard PCR targeting a 347-bp fragment of the $c y t b$ gene as previously described [38]. PCR amplification was performed in a Peltier PTC- 200 model thermal cycler (MJ Research Inc, Watertown, MA, USA). The final volume PCR consisted of a $25 \mu$, including $12.5 \mu$ l Amplitaq gold master mixes, $0,5 \mu \mathrm{M}$ of each primer, $5 \mu \mathrm{l}$ DNA template, and water. The thermal cycling profile comprised an incubation step at $95^{\circ} \mathrm{C}$ for $15 \mathrm{~min}, 40$ cycles of 1 min each at $95{ }^{\circ} \mathrm{C}, 30 \mathrm{~s}$ at $56^{\circ} \mathrm{C}$ and $1 \mathrm{~min}$ at $72{ }^{\circ} \mathrm{C}$, followed by a final extension step of $5 \mathrm{~min}$ at $72{ }^{\circ} \mathrm{C}$. The results of the amplification were then confirmed by electrophoresis in agarose gel. To proceed with the purification of the PCR products, a NucleoFast 96 PCR plates (Macherey-Nagel EURL, Hoerdt, France) were used according to the manufacturer's instructions. The amplicons were then sequenced using the Big Dye Terminator Cycle Sequencing Kit (Perkin Elmer Applied Biosystems, Foster City, CA) with an ABI automated sequencer (Applied Biosystems). The electropherograms obtained were then assembled and edited using the ChromasPro software (ChromasPro 1.7, Technelysium Pty Ltd., Tewan- tin, Australia) and compared with those available in GenBank database by NCBI BLAST (http://blast.ncbi.nlm.nih.gov/Blast.cgi).

2.2.3. Sequences and phylogenetic diversity analysis 
In order to assess clade diversity in human lice, the total Guinean head lice-cytb sequences obtained in this study were combined and compared with the worldwide P. humanus-cytb mitochondrial sequences previously reported (Supplementary data: Table S1). ClustalW alignments were performed using MEGA software version 6.06. Thereafter, the Maximumlikelihood (ML) analysis was also performed in MEGA6 using the Kimura 2-parameter model for nucleotide sequences under 1000 bootstrap replicates [43]. The cytb from $P$. schaeffi (AY696067) was used as an outgroup. A median-joining (MJ) network was also constructed in order to investigate the possible relationships between the haplotypes, using the method of Bandelt performed with NETWORK10.0.0 program (www.fluxusengineering.com/sharenet.htm) [44].

\subsection{Molecular investigation of lice ecotype}

2.3.1. Louse ecotype investigation by multiplex qPCR assays

In this study, all lice specimens were collected from the scalp region of each individual; however, we were curious to further study our lice ecotypes. Therefore, all lice samples were analyzed by multiplex real-time PCR, targeting a portion of the PHUM540560 gene. This assay was developed to discriminate between body lice and head lice belonging to clade A [41], which has always been known as a worldwide clade that encompass the two ecotypes [31,34]. This assay had never been used to study lice belonging to other clades. We used a clade A head and body louse as positive controls.

2.3.2. Louse ecotype investigation by conventional PCR assays and sequencing

To analyze the sequences of the PHUM540560 gene of the Guinean human lice, 40 specimens were randomly selected. Additionally, clade A-human lice were randomly selected from our lice collection, including 7 specimens of Orlando strain from our rabbit rearing colony 
and 11 Algerian body lice collected from homeless people [45]. These samples were then subjected to standard PCR and sequencing of the target PHUM540560 gene. The sequences obtained were aligned with the specific PHUM540560 sequences of the clade A-body and head lice, described thorough the previous study [41]. Alignment was performed using the BioEdit v 7.0.5.3 software (available online: http://en.bio-soft.net/ format/BioEdit.html), in order to reveal the rearranged sequences of the head lice PHUM540560 gene collected in Guinea compared with those of the clade A-human lice.

\subsection{Screening for the presence of pathogen's DNA}

\subsubsection{Identification of pathogen's DNA by qPCR assays}

In order to screen louse-borne pathogens, a qPCR was performed for all head lice samples targeting the presence of various pathogenic bacteria: Rickettsia spp., Borrelia spp., B. quintana, Y.pestis, C. burnetii, Anaplasma spp. and Acinetobacter spp., using specific primers and probes, as previously reported (Table1).

Initially, we pooled our DNA's template into 8 samples of $10 \mu 1 /$ specimen for each pool; each sample was in a proportion of $1 \mathrm{Log}$ of its initial concentration. Modifications of the qPCR cycles threshold $(\mathrm{Ct})$ from $40 \mathrm{Ct}$ to $45 \mathrm{Ct}$ were performed to ensure that no potentially positive samples were missing from each pool. Thereafter, each louse from each positive pool with a $\mathrm{Ct} \leq$ 38, was tested individually. The qPCR analysis was performed as described above for the $c y t b$, a positive control of the targeted DNA and a negative control of master mixtures were included in each PCR run. Samples positive for Acinetobacter spp. were subjected to qPCR specific for Acinetobacter baumannii, targeting the OmpA/MotB gene, as previously reported (Table 1).

2.4.2. Identification of pathogen's DNA by conventional PCR and sequencing 
In order to identify the species of Acinetobacter, positive samples from qPCR were subjected to a standard PCR targeting a portion of the $r p o B$ gene (zone1) using the primers and conditions previously described (Table 1). Successful amplification was confirmed by electrophoresis via agarose gel, amplicons were prepared and sequenced using similar methods as described above. Due to a low specificity of above-mentioned primers, a new specific PCR system was designed in this study in order to amplify only and specifically the DNA of Acinetobacter spp. targeting a different portion of the same ropB gene. The Fasta-file was constructed from the sequences available in the GenBank database for all Acinetobacter species as well as for Moraxella spp. and Psychrobacter spp. Sequences were aligned using BioEdit v 7.0.5.3 software (available online: http://en.bio-soft.net/ format/BioEdit.html) to reveal conserved areas as target regions for Acinetobacter spp. specific primers. This region was submitted in Primer3 software v. 0.4.0 (available online: http://primer3.ut.ee/) to determine candidate primers based on the criteria for the primer design. PCR primers settings were in accordance with the guidelines as previously described and as recommended by InvitrogenTM (available online: https://www. thermofisher.com/fr/fr/home/brands/invitrogen.html) and Applied BiosystemsTM (available online:

https://www.thermofisher.com/fr/fr/home/brands/applied-biosystems.html). Then, the melting temperatures of the primers were tested using the free online software Oligo Analyzer 3.1 (available online: https://eu.idtdna.com/calc/analyzer). Primers were then synthesized by Eurogentec (Liège, Belgium). PCR systems and their target gene are described in Table 1.

\subsection{Acinetobacter resistance to carbapenem}


To eventually investigate this paradigm in our study, all positive A. baumannii-Guinean head lice were subjected to qPCR analyzes targeted three carbapenem resistant encoding genes including bla $\mathrm{OXX}_{\text {OX3 }}$, bla $\mathrm{OXX}_{\text {OX-24 }}$ and bla $\mathrm{OXX}_{-58}$, as previously described [51] (Table 1). Results were considered positive when the cycle threshold value of real-time PCR is $\leq 35$. 
Table 1. Real time PCR and conventional PCR primers and probes used in this study.

\begin{tabular}{|c|c|c|c|}
\hline Target & Name & Primers and probes $\left(5^{\prime}-3^{\prime}\right)$ & Source \\
\hline \multirow{14}{*}{ Pediculus humanus } & \multirow{4}{*}{$\begin{array}{r}\text { Cytb. } \\
\text { Duplex A/D }\end{array}$} & FAM-CATTCTTGTCTACGTTCATATTTGG-TAMRA & \multirow{8}{*}[18]{} \\
\hline & & VIC-TATTCTTGTCTACGTTCATGTTTGA-TAMRA & \\
\hline & & F_ GATGTAAATAGAGGGTGGTT & \\
\hline & & R_GAAATTCCTGAAAATCAAAC & \\
\hline & \multirow{4}{*}{$\begin{array}{c}C y t b . \\
\text { Duplex B/C-E }\end{array}$} & FAM-GAGCTGGATAGTGATAAGGTTTAT- TAMRA & \\
\hline & & VIC-CTTGCCGTTTATTTTGTTGGGGTTT-TAMRA & \\
\hline & & F_tTAGAGCGMTTRTTTACCC & \\
\hline & & R_AYAAACACACAAAAMCTCCT & \\
\hline & \multirow{2}{*}{$C y t b$} & F_ GAGCGACTGTAATTACTAATC & \multirow{2}{*}{ [38] } \\
\hline & & R_CAACAAAATTATCCGGGTCC & \\
\hline & \multirow{4}{*}{$\begin{array}{l}\text { Phum54 } \\
0560\end{array}$} & FAM-CGATCACTCGAGTGAATTGCCA-TAMRA & \multirow{4}{*}{ [41] } \\
\hline & & VIC-CTCTTGAATCGACGACCATTCGCT-TAMRA & \\
\hline & & GTCACGTTCGACAAATGTT & \\
\hline & & TTTCTATAACCACGACACGATAAAT & \\
\hline \multirow{3}{*}{$\begin{array}{l}\text { Rickettsia spp. citrate } \\
\text { synthase (gltA) }\end{array}$} & \multirow{3}{*}{ RKNDO3 } & FAM-CTATTATGCTTGCGGCTGTCGGTTC-TAMRA & \multirow{3}{*}{ [46] } \\
\hline & & F_GTGAATGAAAGATTACACTATTTAT & \\
\hline & & R_GTATCTTAGCAATCATTCTAATAGC & \\
\hline \multirow{3}{*}{$\begin{array}{l}\text { Borrelia spp. } 16 S \\
\text { ribosomal RNA }\end{array}$} & \multirow{3}{*}{ Bor16S } & FAM-CCGGCCTGAGAGGGTGAACGG-TAMRA & \multirow{3}{*}{ [47] } \\
\hline & & F_AGCCTTTAAAGCTTCGCTTGTAG & \\
\hline & & R_GCCTCCCGTAGGAGTCTGG & \\
\hline \multirow[t]{2}{*}{ Bartonella quintana } & \multirow{2}{*}{$\begin{array}{r}\text { yopP - } \\
\text { Hypothetical }\end{array}$} & FAM-GCGCGCGCTTGATAAGCGTG-TAMRA & \multirow{2}{*}{ [48] } \\
\hline & & F_GATGCCGGGGAAGGTTTTC & \\
\hline
\end{tabular}




\begin{tabular}{|c|c|c|c|}
\hline & $\begin{array}{l}\text { intracellular } \\
\text { effector }\end{array}$ & R_GCCTGGGAGGACTTGAACCT & \\
\hline \multirow{3}{*}{ Yersinia pestis } & \multirow{3}{*}{$P L A$} & FAM-TCCCGAAAGGAGTGCGGGTAATAGG-TAMRA & \multirow{3}{*}[13]{} \\
\hline & & F_ATG GAG CTT ATA CCG GAA AC & \\
\hline & & R_GCG ATA CTG GCC TGC AAG & \\
\hline \multirow{3}{*}{ Coxiella burnetii } & \multirow{3}{*}{ ISI111 } & FAM- CCGAGTTCGAAACAATGAGGGCTG-TAMRA & \multirow{3}{*}{ [49] } \\
\hline & & F_ CGCTGACCTACAGAAATATGTCC & \\
\hline & & R_GGGGTAAGTAAATAATACCTTCTGG & \\
\hline \multirow{3}{*}{$\begin{array}{l}\text { Anaplasma spp. } 23 S \\
\text { ribosomal } R N A\end{array}$} & \multirow{3}{*}{ TtAna } & FAM-GGATTAGACCCGAAACCAAG-TAMRA & \multirow{3}{*}[50]{} \\
\hline & & F_TGACAGCGTACCTTTTGCAT & \\
\hline & & R_TGGAGGACCGAACCTGTTAC & \\
\hline \multirow{7}{*}{$\begin{array}{c}\text { Acinetobacter spp. } \\
\text { RNA polymerase } \beta \text { subunit } \\
\text { gene }\end{array}$} & \multirow{3}{*}{ rров } & FAM-CGCGAAGATATCGGTCTSCAAGC-TAMR & \multirow{3}{*}[51]{} \\
\hline & & F_TACTCATATACCGAAAAGAAACGG & \\
\hline & & R_GGYTTACCAAGRCTATACTCAAC & \\
\hline & \multirow{2}{*}{$\begin{array}{c}r p o B \\
\text { (zone1) }\end{array}$} & F_TAYCGYAAAGAYTTGAAAGAAG & \multirow{2}{*}[52]{} \\
\hline & & R_CMACACCYTTGTTMCCRTGA & \\
\hline & \multirow{2}{*}{$\begin{array}{c}r p o B \\
\text { (zone1) }\end{array}$} & F_ TACAARATCTTYGAAGAAGC & \multirow{2}{*}{ This study } \\
\hline & & R_CCACAACADAGDTTGTARRA & \\
\hline \multirow{3}{*}{$\begin{array}{c}\text { Acinetobacter } \\
\text { baumanii. Type VI secretion } \\
\text { system OmpA/MotB }\end{array}$} & \multirow{3}{*}{$\underset{B}{O m p A / M o t}$} & FAM_AAGTCGCCAAGAAACCTTGA_TAMRA & \multirow{3}{*}[53]{} \\
\hline & & F_TCAACATCACAATCTTTAGTAGCTGA & \\
\hline & & R_CGCTCTTGCCAGCATAAAGA & \\
\hline \multirow{4}{*}{ Carbapenems genes } & \multirow{3}{*}{$O X A-23$} & 6-FAM-CCAGTCTATCAGGAACTTGCGCGA-BHQ_1 & \multirow{4}{*}[56]{} \\
\hline & & F_GACACTAGGAGAAGCCATGAAG & \\
\hline & & R_CAGCATTACCGAAACCAATACG & \\
\hline & & TET-AGTAACACCCATTCCCCATCCACTTTT-IABkFQ & \\
\hline
\end{tabular}




\begin{tabular}{ccc}
\hline OXA-24 & F_GATGACCTTGCACATAACCG \\
\cline { 2 - 3 } & & R_CAGTCAACCAACCTACCTGTG \\
\cline { 2 - 3 } & CXA-58 & Cy5-TGGACCAATACGACGTGCCAATTCT-IAbRQSp \\
\cline { 2 - 2 } & & CAAGATTTTACTTTGGGCGAAGC \\
\hline
\end{tabular}

2 
3

4

10 DNA concentration. The generated Guinean sequences were then aligned and combined with all

11 sequences available for $c y t b$ haplotypes and were then used to construct a maximum-likelihood

12 (ML) tree (Fig. 2) and a median-joining (MJ) network (Figs. 3). The results revealed the

13 existence of 8 haplotypes, including 6 new haplotypes referred here as E68, E69, E70, E71, E72

14 and E73 with the attributed GenBank accession numbers MT981014-MT981019 respectively. In

15 addition, E39 and E48, the two most prevalent haplotypes present in clade E, accounted for the

16 majority of our lice samples. Indeed, most of our head lice specimens, 96 (68.1\%), belonged to

17 the haplotype E39, $12(8.5 \%)$ to the haplotype E48 and $33(23.4 \%)$ to the six novel haplotypes,

18 with $10(30.3 \%)$ to E68, $8(24.3 \%)$ to E69, $1(3 \%)$ to E70, 1(3\%) to E71, 1(3\%) to E72 and 12

$19(36.4 \%)$ to E73. 


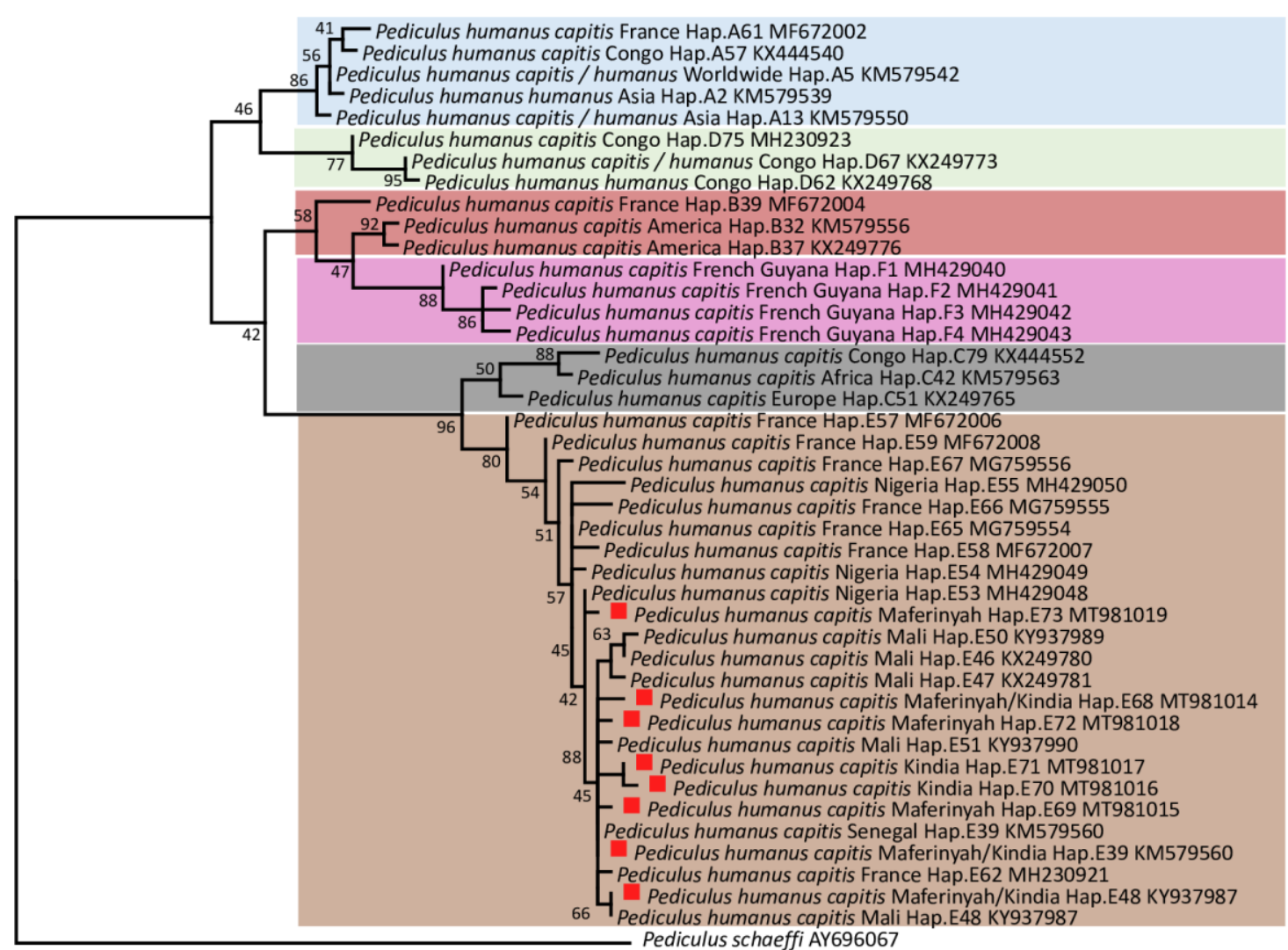

Clade B

Clade F

Clade C

Figure 2. Maximum-likelihood (ML) phylogenetic tree of the mitochondrial $c y t b$ gene showing the relationship of haplotypes

23 identified in this study with other P. humanus haplotypes reported in the literature. Phylogenetic inference was conducted in MEGA 7

24 using the maximum likelihood method under the Kimura 2-parameter with 1000 bootstrap replicates. There were a total of 141

25 positions in the final dataset. 


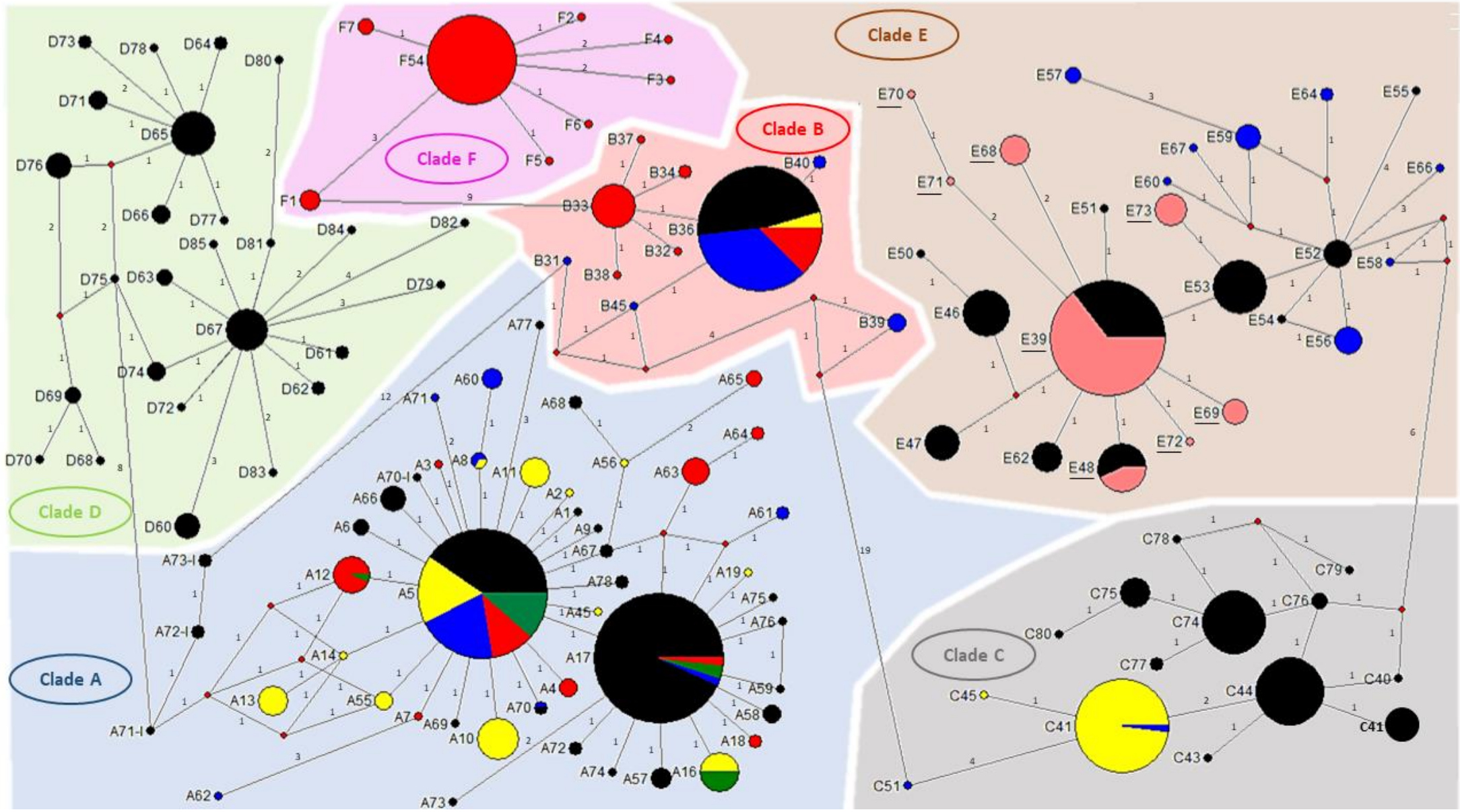

Figure 3. Cytb haplotype networks of human body and head lice including our samples. Each circle indicates a unique

28 haplotype, and variations in circle size are proportional to haplotype frequencies. Pie colors and sizes in circles represent the

30 mutations. The types of haplotypes identified in this study are underlined. 
Besides, all Pediculus humanus lice were tested by multiplex qPCR targeting the

32 PHUM540560 gene to investigate their ecotype; this method was used previously to distinguish

33 between head and body lice belonging to clade A. All our specimens were collected by the

34 patients from their scalp hair, and belong to clade E. Using this method, all the 155 Guinean head

35 lice specimens exhibited a real-time PCR FAM-labeled probe amplification specific to the body

36 lice profile, as demonstrated previously [41]. These results confirm the fact that the

37 PHUM540560- multiplex qPCR is a restricted molecular tool to differentiate only between clade

38 A-human lice. Based on these data, we proceeded with the analysis of the PHUM540560 gene

39 sequences of our samples and those belonging to clade A reported in the literature [41]. For this

40 purpose, diverse human lice specimens encompassing both ecotypes were randomly selected

41 from our lice collection. These samples were then subjected to standard PCR and sequencing of

42 the targeted PHUM540560 gene. The obtained sequences were aligned with the specific

43 PHUM540560 sequences of body and head lice. Alignment was conducted using the BioEdit v

44 7.0.5.3 software (available online: http://en.bio-soft.net/ format/BioEdit.html), in order to reveal

45 the rearranged sequences of the Guinean-head lice PHUM540560 gene and to compare the

46 polymorphisms obtained with those of the clade A body and head lice.

47 The comparison of the PHUM540560 gene of Clade A-head lice and clade A-body lice

48 revealed the presence of 22 single nucleotides polymorphisms (SNPs) in the head lice-

49 PHUM540560 gene. The first two point mutations situated on the first exon and the remainder of

50 the polymorphisms were spread throughout the first intron [41]. Interestingly, none of our clade

51 E-head lice showed the clade A head lice-PHUM540560 gene profile. Indeed, 33/40 (82.5\%) of

52 Guinean head lice are characterized by the absence of all the above-mentioned SNPs present in

53 clade A-Amazonian head lice, thus exhibiting a clade A-body lice profile, while 7/40 (17.5\%) 
54 samples displayed different kinds of SNPs: 4/7 (57.1\%) revealed the existence of 3 SNPs, 1/7

55 (14.3\%) the existence of 18 SNPs and 1/7 (14.3\%) the existence of 20 SNPs. Regarding our body

56 lice tested, all (18 samples) had the same PHUM540560 gene profile of body lice reported by

57 Drali et al. [41]. Details of head lice numbers, codes and PHUM540560 gene SNPs profiles are

58 listed in Table 2. Details of PHUM540560 sequences alignments are listed in Figure 2.

59

60

Table 2. PHUM540560 gene SNPs profile of Guinean head lice compared to clade A-

61 human lice.

\begin{tabular}{cccc}
\hline N. of HL & Code Sample & N. of SNPs & Type of SNPs \\
\hline 1 & S137 & 18 & All except 13, 14, 6 and 7 \\
\hline 2 & S72, S100 & 20 & All except 13 and 14 \\
\hline 4 & S66, S67, S69, S140 & 3 & 1,2 and 12 \\
\hline 33 & $\begin{array}{c}\text { Remaining tested samples } \\
(45,73, \text { 105 and 111 in Fig. 2) }\end{array}$ & 0 & 0 \\
\hline
\end{tabular}

62 N: Number; HL: head lice; S: sample, SNPs: Single Nucleotide Polymorphisms 


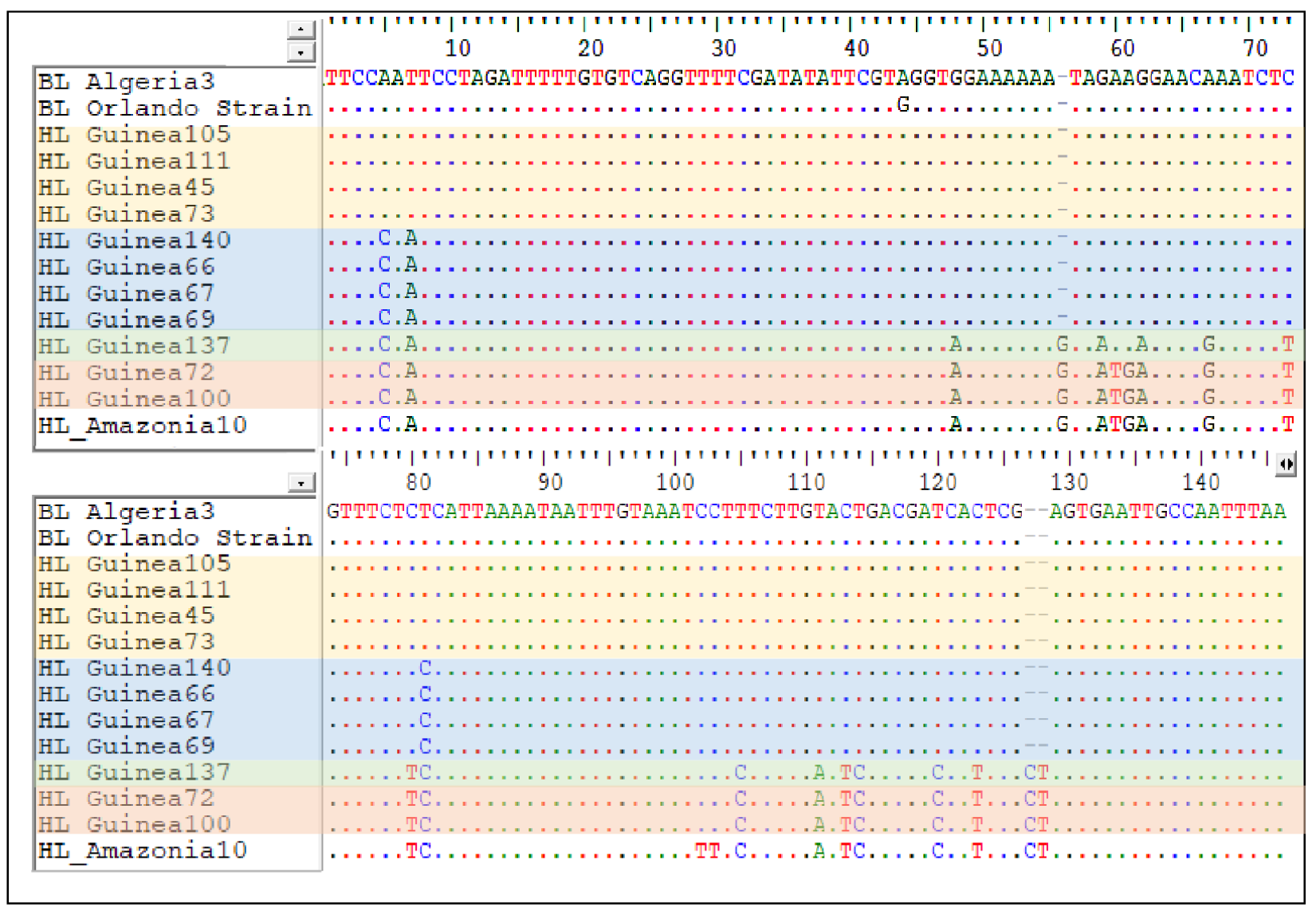

Figure 4. Alignments of a portion of Guinean head lice-Phum_PHUM540560 gene

66 literature. HL_Amazonia10 [40] represent the 22 SNPs that are specific to clade A-head lice.

67 HL_Guinea group contains 7 specimens: yellow block nucleotides represent 22 SNPs that are

68 specific to body lice; blue block nucleotides represent 3 SNPs that are specific to body lice;

69 green block nucleotides represent 18 SNPs that are specific to body lice and orange block

70 nucleotides represents 20 SNPs that are specific to P.h. humanus.

71 BL: body louse; HL: head louse; P.h. humanus strain USDA 1103172108290 Phum_PHUM540560 (gene

72 sequence available in GenBank accession N. NW_002987859.1). 
In addition, none of the head lice samples revealed the presence of Rickettsia spp., $B$.

77 quintana, Borrelia spp., Y. pestis, C. burnetii and Anaplasma spp. However, the DNA of

78 Acinetobacter spp. was found in 14/155 (9\%) samples collected from 11/46 (24.5\%) individuals.

79 All positive samples were collected in 14/130 (10.8\%) Maférinyah. Positive Acinetobacter

80 specimens were then tested for a specific $A$. baumannii-qPCR, revealing that 2 of the 14 (14.3\%)

81 samples were positive, these samples belonged to the haplotype E39 and were collected from 2

82 different patients in Maférinyah. The first amplification of Acinetobacter DNA in positive head

83 lice samples showed the presence of the DNA from Moraxella bacterium and Psychrobacter

84 spp., which explains the low specificity of the target gene-amplification by these primers. We

85 designed a more specific system targeting the $r p o B$ gene of this bacterium and, due to the low

86 concentration of Acinetobacter DNA in our positive head lice, we succeeded in amplifying the

87 DNA of the pathogen in only $7 / 14$ positive samples. Sequencing and blast analysis of $350-b p s$

88 fragment $r p o B$ gene revealed that $6 / 7$ (85.7\%) of our sequences shared 99-100\% identity with 4

89 Acinetobacter species including: 2/7 (28.6\%) E69 and E39 head lice matching with

90 Acinetobacter nosocomialis, 2/7 (28.6\%) E39 and E48 head lice with Acinetobacter variabilis,

$91 \quad$ 1/7 (14.2\%) E69 head louse with Acinetobacter towneri and finally, 1/7 (14.2\%) E48 specimen

92 with Acinetobacter haemolyticus. The remaining generated sequence 1/7 (14.3\%), shared a lower

93 similarity (<94\%, coverage $100 \%)$ with two Acinetobacter species: A. johnsonii and A.

94 venetianus, suggesting that this Acinetobacter is a potential new specie, named here "Candidatus

95 Acinetobacter P.h capitis Guinea". This positive sample belonged to haplotype E39. All

96 positives head lice for Acinetobacter species were collected at Maférinyah, and none at Kindia.

97 Interestingly, one of the patients included in this study was infested with four head lice, two of

98 them were infected with A. nosocomialis and A. variabilis; belonging respectively to haplotypes 
99 E48 and E39. The remaining seven of the 14 sequences (50\%) also had similarities with

100 Acinetobacter spp. However, the sequences were of poor quality, which is assumed to be due to

101 the co-infection of several Acinetobacter species. The phylogenetic tree of all Acinetobacter

102 species identified in this study is presented in Fig.4.

103 In our study, none of the DNA A. baumannii samples tested positive for carbapenem's-

104 resistant encoding genes $\left(\right.$ bla $_{\text {OXA-21 }}$, bla $_{\text {OXA-24 }}$, bla $\left._{\text {OXA-58 }}\right)$.

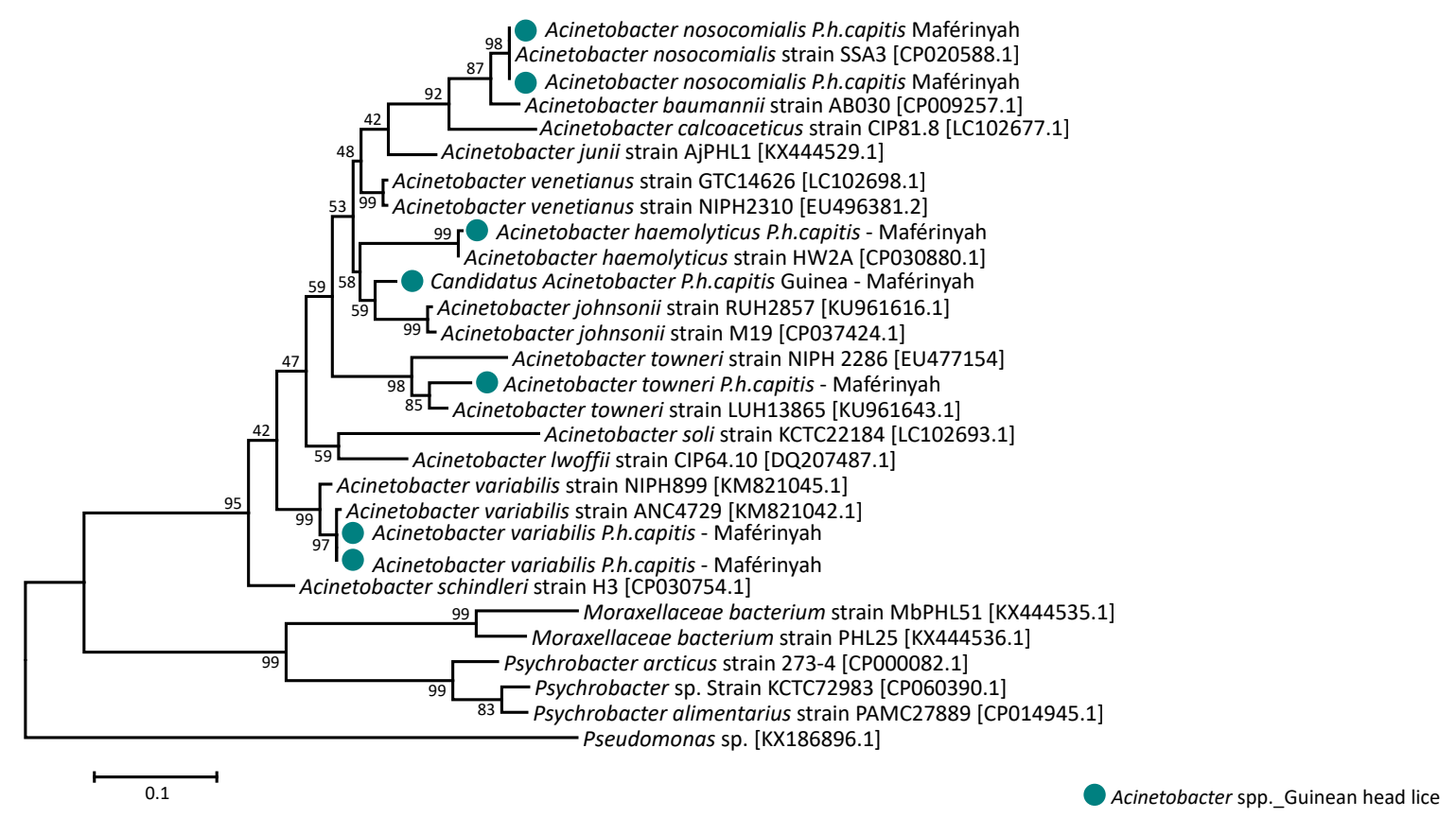

Figure 5. Phylogenetic tree highlighting the position of the Acinetobacter species

107 identified in the head lice collected from Guinea compared to Acinetobacter spp. available in the

108 GenBank database. Phylogenetic inferences were conducted in MEGA 7 using the maximum

109 likelihood method based on the Kimura 2-parameter model for nucleotide sequences. Statistical

110 support for internal branches of the tree was evaluated by bootstrapping with 1000 replicates.

111 There was a total of 7 positions in the final dataset. 


\section{Discussion}

113

To the best of our knowledge, the present study is the first to investigate both the

114 phylogeny and associated pathogens of head lice collected in Guinea. A total of 155 head lice

115 were collected from 47/49 (95.9) females and 2/49 (4.1\%) males living in two different rural and

116 urban areas, Maférinyah, a village, and the city of Kindia, Guinea, West Africa. A genetic study

117 using the qPCR duplex first showed that all the lice samples analyzed belonged to the

118 mitochondrial clade C or E. Standard PCR and sequencing revealed that all the head lice

119 belonged to the haplogroup E. The qPCR duplex method is not discriminative enough for the

120 screening of African human lice, which mainly belong to haplogroups $\mathrm{C}$ and $\mathrm{E}$. In the future, this

121 method should be optimized by a design that also includes a specific clade E monoplex, to obtain

122 a better identification of African human lice, as well as to establish an optimal qPCR duplex for

123 the discrimination of all human lice belonging to all existing haplogroups, including the recently

124 described clade F. The phylogenetic study showed the existence of 8 haplotypes including 6

125 novels described for the first time in this study. The presence of clade $\mathrm{E}$ in both rural and urban

126 communities in Guinean lice is not surprising, as it confirms the high prevalence of the "African

127 endemic" clade E, as previously reported so far [18, 26, 28, 29]. The most prevalent haplotype

128 reported in our head lice is the E39 obtained with $68.1 \%$, followed by the haplotype E48 with

$1298.5 \%$ of the total prevalence. In addition, six new haplotypes were identified in Guinean head

130 lice, including E68 (7.1\%), E69 (5.6\%), E70 (0.71\%), E71 (0.71\%), E72 (0.71\%) and E73

131 (8.5\%). So far, haplogroup E has only been found in head lice collected in West African

132 countries, including Senegal and Mali [18], in head lice samples collected from Nigerians

133 refugees in Algeria [26] and in P.h. capitis collected from migrant communities living in

134 Bobigny, France [25]. However, a recent study showed for the first time the presence of clade E, 
135 more specifically the E62 haplotype in Central Africa, in Congo, suggesting that Congonians are

136 in direct contact with West African populations or travelers arriving form West African countries

137 [28]. More recently, this clade has also been found in head lice collected from individuals in

138 Gabon, belonging to haplotype E46 [29], already reported among lice collected in Mali [18].

139 These results suggest that the significant migratory exchange between Gabon and the Republic

140 of the Congo can be the source for the clade E expansion [29]. In addition, among the 141 head

141 lice $c y t b$ sequences analyzed, 4 lice with two different haplotypes, E39 and E70, were collected

142 from the same 34-year-old woman. In addition, four haplotypes were also identified within the

143 same person infested with 11 lice, in Kindia, belonging to haplotypes E39, E48, E71 and E73.

144 Co-infestations by different mitochondrial DNA clades of human head lice within the same

145 person were reported previously, showing that human lice belonging to different clades can live

146 in sympatry and interbreed [36, 39], including the association of clades A and B [36], clade A

147 and D [14,29], clade A and C [39]. All these results underline the fact that more phylogenetic

148 studies on human lice-mitochondrial clades, from larger sampling zones, with different

149 geographical areas, and more human lice samples, should be carried out to broaden our

150 knowledge of the inter and intra-haplogroup diversity.

151 In this study, we investigated the Phum540560 gene polymorphisms of Guinean head lice

152 belonging to clade E. We could not confirm the ecotype of our head lice samples using the

153 Phum540560-multiplex qPCR, previously used to discriminate between $P$. humanus ecotypes

154 belonging to clade A, therefore, our results are consistent with those reported previously [41], the

155 clade E head lice ecotype cannot be identified by this molecular tool. However, in our study, we

156 were interested in analyzing the Phum_PHUM540560 gene sequences from Guinean head lice to

157 better understand their polymorphism profile. Interestingly, none of our clade E-head lice 
158 showed the clade A head lice-PHUM540560 gene profile. Indeed, 33/40 (82.5\%) of Guinean

159 head lice were characterized by the absence of all the above-mentioned SNPs present in clade A-

160 Amazonian head lice, consequently exhibiting a clade A-body lice profile, while 7/40 (17.5\%)

161 samples showed different kinds of SNPs: 4/7 (57.1\%) revealed the existence of 3 SNPs, 1/7

$162(14.3 \%)$ the existence of 18 SNPs and $1 / 7(14.3 \%)$ the existence of 20 SNPs. These results

163 highlight the fact that the majority of the Clade E-Guinean head lice exhibit the profile of the

164 clade A-body lice, noting that the clade A lice is the origin of clades B and C, where clade B

165 head lice were reported to diverge from clade A between 0.7 and 1.2 Mya, whereas clade $\mathrm{C}$ is

166 even older (ca. 2 Mya) [11]. These results should encourage further study of the polymorphism

167 profile of the PHUM540560 gene from Pediculus humanus belonging to the six divergent

168 mitochondrial clades reported so far. In addition, further studies, with a wider sampling, are

169 necessary to study a larger portion of the Phum_PHUM540560 gene. These investigations will

170 allow a better understanding and will probably lead us to design a more efficient molecular tool,

171 which will be able to discriminate between the two ecotypes. At this point, we can affirm the fact

172 that the morphological, biological and genetic characteristics of $P$. humanus species are almost

173 similar and remain obscure. However, body and head lice are extremely different in their

174 ecological niches, which remain, until now, the main criterion for distinguishing between these

175 two ecotypes.

176 In recent decades, the paradigm that P.h.humanus was the only vector of dangerous

177 diseases has been challenged [8]. Indeed, many studies have reported the presence of several

178 pathogenic agents in head lice specimens collected worldwide [12-30]; thus, demonstrating that

179 the potential pathogen-vector-competence of the head louse is not yet understood [8]. In this

180 study, among all the bacteria examined, we found the presence of Acinetobacter spp. in only 14 
181 head lice infesting 11 individuals. Findings from previous studies reported a worldwide spread

182 of several Acinetobacter species, including A. baumannii, A. junii, A. ursingii, A. johnsonii, A.

183 schindleri, A. lwoffii, A. nosocomialis, A. towneri, A. variabilis, A. radioresistens, A.

184 calcoaceticus, A. soli, A. pittii and potential new species in head lice collected from different

185 population categories, including elementary school children in Algeria [26,27], France [22],

186 Thailand and Georgia-USA [19,24], of the Pygmy population in the Republic of Congo [21],

187 Nigerian refugee children in Algeria [26] and, more recently, in head lice collected from healthy

188 women in Gabon [29], and even in ancient Roman-era head lice remains [32]. The diversification

189 of Acinetobacter species was reported from head lice belonging to the majority of the existing

190 head lice-haplogroups A, D, C, E and B, and in different haplotypes of each haplogroup [11].

191 Among the 14 Acinetobacter positives P.h.capitis samples, we identified the existence of $A$.

192 baumannii, A. nosocomialis, A. variabilis A. towneri and for the first time in head lice $A$.

193 haemolyticus as well as one potential new specie named here "Candidatus Acinetobacter P.h

194 capitis Guinea". Based on these results, we confirmed the diversity of the Acinetobacter species

195 in head lice. Our study is the first to describe the presence of A. haemolyticus in human head lice.

196 A. haemolyticus is a pathogenic bacterium widely distributed in nature and commonly found in

197 soil, water and hospitals. Like A. baumannii, A. johnsonii and A. junii, A. haemolyticus is an

198 important clinical microorganism responsible for nosocomial infections and associated with

199 endocarditis, bacteremia and others types of infections in hospitals [58].

200 Body lice can also be infected by a diverse Acinetobacter species, including A. baumannii,

201 A. johnsonii, A. berezeniae, A. nosocomialis and A. variabilis [23, 45]. Indeed, A. baumannii was

202 isolated for the first time from body lice collected on homeless people in France and,

203 subsequently, the bacterium was detected in body lice collected worldwide [55]. Most of the 
204 Acinetobacter species are pathogenic bacteria that can survive for a long period in the

205 environment and have been associated with carbapenem resistance, especially A. baumannii and

206 A. haemolyticus, because of their multiple resistance to many common antibiotics [58].

207 In recent decades, Acinetobacter bacteria have shown high ability to develop resistance to

208 almost all major classes of antibiotics. So far, the incidence of carbapenem resistance in $A$.

209 baumannii has continued to increase worldwide [54]. In human lice, A. baumannii isolates were

210 remarkably susceptible to carbapenems [55]. Indeed, a study performed on head lice collected in

211 Senegal reported that $21.4 \%$ of the positive $A$. baumannii- head lice harbored a bla OXA-23 $_{2}$

212 carbapenem resistant encoding gene [56]. A precedent study reported for the first time the

213 presence of bla ${ }_{\text {OXA-23 }}$ gene in positive A. baumannii human head lice in Senegal [54]. None of

214 our positive-A. baumannii head lice were positive to the carbapenem's-resistant encoding genes

$215\left(\right.$ bla $_{\text {OXA-21 }}$, bla $_{\text {OXA-24 }}$, bla $\left._{\text {OXA-58 }}\right)$. Further studies are needed to investigate the association between

216 Acinetobacter infections and human lice, the compatibility of Acinetobacter strains present in

217 lice and those responsible for human infections, as well as investigate the carbapenem's-resistant

218 in A. baumannii strain present in human lice.

\section{Conclusion}

Herein, to the best of our knowledge, we report here the first molecular data on the genetic

221 diversity and associated pathogens of head lice collected in Guinea. Overall, polygenetic analysis

222 reveal that all our specimens belonged to haplogroup E within 8 haplotypes, with 6 novels

223 described for the first time in this study. Genetic study of the PHUM540560 Gene

224 polymorphisms profile revealed that the majority of our Guinean head lice exhibit a clade A-

225 body lice PHUM540560 gene polymorphism profile, showing the importance of conducting a

226 more in-depth genetic study of the PHUM540560 gene, targeting human lice belonging to the six 
227 divergent mitochondrial clades to better understand this paradigm. None of the pathogenic

228 bacteria tested were detected in our P. h. capitis samples, except for Acinetobacter spp. for

229 which we were able to identify several species, including A. baumannii, A. nosocomialis, A.

230 variabilis, A. towneri, a potential new specie "Candidatus Acinetobacter P.h capitis Guinea"

231 and, for the first time in head lice, A. haemolyticus. Further studies are needed to study the

232 genetic diversity of Guinean head lice and to evaluate their role as a potential vector for their

233 associated bacteria.

$234 \quad$ Supplementary Materials

235 Table S1. Geographical and frequencies occurrences of $c y t b$ haplotypes of human head

236 and body lice worldwide.

Author contributions: M.L., F.F. and O.M. designed the study. CB and HB supervised the

238 collection of the samples. A.H. and M.L performed the lab work. A.H., M.L. and O.M. carried out

239 the data analysis. A.H. and M.L. wrote the manuscript. A.H, M.L, CB, HB, F.F, D.R, D.M, P.G

240 and O.M revised the manuscript. All authors read and approved the final manuscript.

241 Funding: This study was supported by the Institut Hospitalo-Universitaire (IHU)

242 Méditerranée Infection, the National Research Agency under the program «Investissements

243 d'avenir», reference ANR-10-IAHU-03, the Région Provence-Alpes-Côte d'Azur and European

244 funding FEDER PRIMI.

245 Acknowledgments: We are grateful for the assistant's member who participated in the 246 supervision of the data and samples collection.

247 Conflicts of Interest: The authors declare that they have no competing interests. The funders

248 had no role in the design of the study; in the collection, analyses, or interpretation of the data; in

249 the writing of the manuscript, or in the decision to publish the results. 


\section{References}

1. Light, J.E.; Smith, V.S.; Allen, J.M.; Durden, L.A.; Reed, D.L. Evolutionary history of mammalian sucking lice (Phthiraptera: Anoplura). BMC Evol. Biol. 2010, 10, 292. doi:10.1186/1471-2148-10-292.

2. $\quad$ Reed, D.L.; Smith, V.S.; Hammond, S.L.; Rogers, A.R.; Clayton, D.H. Genetic analysis of lice supports direct contact between modern and archaic humans. PLoS Biol. 2004, 2, e340. doi: 10.1371/journal.pbio.0020340.

3. Raoult, D.; Roux, V. The body louse as a vector of re-emerging human diseases. Clin. Infect. Dis. 1999, 29, 888-911, doi:10.1086/520454.

4. Durden, L.A.; Musser, G.G. The sucking lice (Insecta, Anoplura) of the world: a taxonomic checklist with records of mammalian hosts and geographical distributions. Bull. AMNH no. 218," in Sucking Lice and Hosts. 1994. http://digitallibrary.amnh.org/handle/2246/825 (accessed April 15, 2018).

5. Light, J. E.; Toups, M.A.; Reed, D.L. What's in a name: the taxonomic status of human head and body lice. Mol. Phylogenet. Evol. 2008, 47, 1203-1216. doi: 10.1016/j.ympev.2008.03.014.

6. Raoult, D. A personal view of how paleomicrobiology aids our understanding of the role of lice in plague pandemics. Microbiol. Spectr. 2016, 4 : PoH-0001-2014. doi: 10.1128/microbiolspec. PoH-0001-2014

7. Robinson, D.; Leo, N.; Prociv, P.; Barker, S.C. Potential role of head lice, Pediculus humanus capitis, as vectors of Rickettsia prowazekii. Parasitol. Res. 2003, 90, 209-211. doi:10.1007/s00436-003-0842-5.

8. Kim, J. H.; Min, J.S.; Kang, J.S.; Kwon, D.H.; Yoon, K.S.; Strycharz, J. et al. Comparison of the humoral and cellular immune responses between body and head lice following bacterial challenge. Insect Biochem. Mol Biol. 2011, 41, 332-339.

9. Kim, J.H.; Yoon, K.S., Previte, D.J.; Pittendrigh, B.R.; Clark, J.M.; Lee, S. H. Comparison of the immune response in alimentary tract tissues from body versus head lice following Escherichia coli oral infection. J. Asia Pac. Entomol. 2012, 15, 409-412. doi: 10.1016/j.aspen.2012.05.010

10. Kim, J.H.; Previte, D.J.; Yoon, K.S.; Murenzi, E.; Koehler, J.E.; Pittendrigh, B.R.; Lee, S.H.; Clark, J.M. Comparison of the proliferation and excretion of Bartonella quintana between body and head lice following oral challenge. Insect Mol. Biol. 2017, 26, 266-276, doi:10.1111/imb.12292. 
11. Amanzougaghene, N.; Fenollar, F.; Raoult, D.; Mediannikov, O. Where are we with human lice? A review of the current state of knowledge. Front.Cell.Infect.Microbiol. 2020, 9, 474, doi:10.3389/fcimb.2019.00474.

12. Sasaki, T.; Poudel, S.K.S.; Isawa, H.; Hayashi, T.; Seki, N.; Tomita, T.; et al. First molecular evidence of Bartonella quintana in Pediculus humanus capitis (Phthiraptera: Pediculidae), collected from Nepalese children. J. Med. Entomol. 2006, 110112. doi: 10.1603/0022-2585(2006)043[0110: fmeobq]2.0.co;2.

13. Piarroux, R.; Abedi, A. A., Shako; J.-C., Kebela; B., Karhemere; S., Diatta; G., et al. Plague epidemics and lice, Democratic Republic of the Congo. Emerg Infect Dis, 2013, 19, 505-506.doi: 10.3201/eid1903.121542.

14. Drali, R.; Shako, J.-C.; Davoust, B.; Diatta, G.; and Raoult, D. A new clade of African body and head lice infected by Bartonella quintana and Yersinia pestis-Democratic Republic of the Congo. Am. J. Trop. Med. Hyg. 2015, 990-993. doi: 10.4269/ajtmh.140686.

15. Boutellis, A.; Mediannikov, O.; Bilcha, K. D.; Ali, J.; Campelo, D.; Barker, S. C. et al. Borrelia recurrentis in head lice, Ethiopia. Emerg. Infect. Dis. 2013, 796-798. doi: 10.3201/eid1905.121480.

16. Angelakis, E.; Diatta, G.; Abdissa, A.; Trape, J.-F.; Mediannikov, O.; Richet, H. et al. Altitude-dependent Bartonella quintana genotype $\mathrm{C}$ in head lice, Ethiopia. Emerg. Infect. Dis. 2011, 2357-2359. doi: 10.1111/j.1574-695X.2011.00804.x .

17. Sangaré, A.K.; Boutellis, A.; Drali, R.; Socolovschi, C.; Barker, S. C.; Diatta, G. et al. Detection of Bartonella quintana in African body and head lice. Am. J. Trop. Med. Hyg. 2014, 294-301.doi: 10.1016/j.ijantimicag.2016.01.001.

18. Amanzougaghene, N.; Fenollar, F.; Sangaré, A. K.; Sissoko, M. S.; Doumbo, O. K.; Raoult, D. Detection of bacterial pathogens including potential new species in human head lice from Mali. PLoS ONE. 2017, e0184621. doi: 10.1371/journal.pone.0184621.

19. Eremeeva, M.E.; Capps, D.; Winful, E.B.; Warang, S.S.; Braswell, S.E., Tokarevich, N.K., et al. Molecular markers of pesticide resistance and pathogens in human head lice (Phthiraptera: Pediculidae) from rural Georgia, USA. J. Med. Entomol. 2017, 1067-1072. doi: 10.1093/jme/tjx039.

20. Boutellis, A.; Veracx, A.; Angelakis, E.; Diatta, G.; Mediannikov, O.; Trape, J.- F. et al. Bartonella quintana in head lice from Sénégal. Vector Borne Zoonotic Dis. 2012, 564-567. doi: 10.1089/vbz.2011.0845. 
21. Amanzougaghene, N.; Akiana, J.; Mongo Ndombe, G.; Davoust, B.; Nsana, N.S.; Parra, H.-J.; Fenollar, F.; Raoult, D.; Mediannikov, O. Head Lice of Pygmies Reveal the Presence of Relapsing Fever Borreliae in the Republic of Congo. PLoS Negl.Trop.Dis. 2016, 10, e0005142. doi: 10.1371/journal.pntd.0005142.

22. Bouvresse, S.; Socolovshi, C.; Berdjane, Z.; Durand, R.; Izri, A.; Raoult, D. et al. No evidence of Bartonella quintana but detection of Acinetobacter baumannii in head lice from elementary schoolchildren in Paris. 34, 475-477. Comp. Immunol. Microbiol. Infect. Dis. 2011, 34.doi: 10.1016/j.cimid.2011.08.007.

23. Kempf, M.; Abdissa, A.; Diatta, G.; Trape, J.-F.; Angelakis, E., Mediannikov, O., et al. Detection of Acinetobacter baumannii in human head and body lice from Ethiopia and identification of new genotypes. Int. J. Infect. Dis. 2012, e680-683. doi: 10.1016/j.ijid.2012.05.1024

24. Sunantaraporn, S.; Sanprasert, V.; Pengsakul, T.; Phumee, A.; Boonserm, R.; Tawatsin, A.; Thavara, U.; Siriyasatien, P. Molecular survey of the head louse Pediculus humanus capitis in Thailand and its potential role for transmitting Acinetobacter spp. Parasit. Vectors. 2015, 8, 127, doi:10.1186/s13071-015-0742-4.

25. Candy, K., Amanzougaghene, N., Izri, A., Brun, S., Durand, R., Louni, M., et al. Molecular survey of head and body lice, Pediculus humanus, in France. Vector Borne Zoonotic Dis. 2018, 243-251. doi: 10.1089/vbz.20.

26. Louni, M.; Amanzougaghene, N.; Mana, N.; Fenollar, F.; Raoult, D.; Bitam, I.; Mediannikov, O. Detection of bacterial pathogens in clade $\mathrm{E}$ head lice collected from Niger's refugees in Algeria. Parasit. Vectors. 2018, 11, 348, doi:10.1186/s13071-018-29305.

27. Mana, N.; Louni, M.; Parola, P.; Bitam, I. Human head lice and pubic lice reveal the presence of several Acinetobacter species in Algiers, Algeria. Comp. Immunol. Microbiol. Infect. Dis. 2017, 33-39. doi: 10.1016/j.cimid.2017.06.003

28. Boumbanda Koyo, C.S.; Amanzougaghene, N.; Davoust, B.; Tshilolo, L.; Lekana-Douki, J.B.; Raoult, D.; Mediannikov, O.; Fenollar, F. Genetic diversity of human head lice and molecular detection of associated bacterial pathogens in Democratic Republic of Congo. Parasit. Vectors. 2019, 12, 290, doi:10.1186/s13071-019-3540-6.

29. Boumbanda-Koyo, C.S.; Mediannikov O., Amanzougaghene N., OyegueLiabagui S.L.; Imboumi-Limoukou, R.K.; Raoult, D. ; Lekana-Douki, J.B. Fenollar, F. Molecular identification of head lice collected in Franceville (Gabon) and their associated bacteria. Parasites \& Vectors, 2020. 13, 410. doi: 10.1186/s13071-020-04293-x. 
30. Amanzougaghene, N.; Mediannikov O.; Anh Ly T.D.; Gautret P.; Davoust B.; Fenollar F.; Izri A. Molecular investigation and genetic diversity of Pediculus and Pthirus lice in France. Parasites \& Vectors, 2020, 13, 177. doi: 10.1186/s13071-020-04036-y.

31. Ashfaq, M.; Prosser, S.; Nasir, S.; Masood, M.; Ratnasingham, S.; Hebert, P.D.N. High diversity and rapid diversification in the head louse, Pediculus humanus (Pediculidae: Phthiraptera). Sci. Rep. 2015, 5, 14188. doi:10.1038/srep14188.

32. Amanzougaghene, N.; Mumcuoglu, K.Y.; Fenollar, F.; Alfi, S.; Yesilyurt, G.; Raoult, D.; Mediannikov, O. High Ancient Genetic Diversity of Human Lice, Pediculus humanus, from Israel Reveals New Insights into the Origin of Clade B Lice. PLOS ONE. 2016, 11, e0164659, doi: 10.1371/journal.pone.0164659.

33. Amanzougaghene, N.; Fenollar, F.; Davoust, B.; Djossou, F.; Ashfaq, M.; Bitam, I.; et al. Mitochondrial diversity and phylogeographic analysis of Pediculus humanus reveals a new Amazonian clade "F." Infect. Genet. Evol. 2019, 1-8. doi: 10.1016/j.meegid.2019.02.006.

34. Ascunce, M. S.; Fane, J., Kassu; G., Toloza; A. C., Picollo, M. I.; GonzálezOliver, A. et al. Mitochondrial diversity in human head louse populations across the Americas. Am. J. Phys. Anthropol. 2013, 118-129. doi: 10.1002/ajpa.22336.

35. Raoult, D.; Reed, D.L.; Dittmar, K.; Kirchman, J.J.; Rolain, J.; Guillen, S.; Light, J.E. Molecular Identification of Lice from Pre-Columbian Mummies. J. Infect. Dis. 2008, 197, 535-543. doi:10.1086/526520.

36. Boutellis, A.; Bitam, I.; Fekir, K.; Mana, N.; Raoult, D. Evidence that clade A and clade B head lice live in sympatry and recombine in Algeria. Med. Vet. Entomol. 2015, 94-98. doi: 10.1111/mve.12058.

37. Al-Shahrani, S.A.; Alajmi, R.A.; Ayaad, T.H.; Al-Shahrani, M.A.; Shaurub, E.-S.H. Genetic diversity of the human head lice, Pediculus humanus capitis, among primary school girls in Saudi Arabia, with reference to their prevalence. Parasitol. Res. 2017, 2637-2643. doi: 10.1007/s00436-017-5570-3

38. Li, W.; Ortiz, G.; Fournier, P-E.; Gimenez, G.; Reed, D.L.; Raoult, D. Genotyping of Human Lice Suggests Multiple Emergences of Body Lice from Local Head Louse Populations. PLoS Negl. Trop. Dis. 2010, 4, 10. doi: e641. doi: 10.1371/journal.pntd.0000641. 
39. Veracx, A., Boutellis, A., Merhej, V., Diatta, G., Raoult, D. Evidence for an African Cluster of Human Head and Body Lice with Variable Colors and Interbreeding of Lice between Continents. PLoS One. 2012, 7: e37804. doi:10.1371/ journal.pone.0037804.

40. Olds, B.P.; Coates, B.S.; Steele, L.D.; Sun, W.; Agunbiade, T.A. et al. Comparison of the transcriptional profiles of head and body lice. Insect Mol Biol, 2012, 21: 257-268. doi: 10.1111/j.1365-2583.2012.01132.x.

41. Drali, R.; Boutellis, A.; Raoult, D.; Rolain, J.M.; Brouqui, P. Distinguishing Body Lice from Head Lice by Multiplex Real-Time PCR Analysis of the Phum_PHUM540560 Gene. PLoS ONE. 2013, 8, e58088. doi: 10.1371/journal.pone.0058088.

42. La Scola, B.; Fournier, P.-E.; Brouqui, P.; Raoult, D. Detection and Culture of Bartonella quintana, Serratia marcescens, and Acinetobacter spp. from Decontaminated Human Body Lice. J. Clin. Microbiol. 2001, 39, 1707-1709. doi:10.1128/JCM.39.5.17071709.2001.

43. Tamura K.; Stecher G.; Peterson D.; Filipski A.; Kumar S. MEGA6: Molecular Evolutionary Genetics Anal- ysis version 6.0. Mol Biol Evol. 2013, 30: 27252729. https://doi.org/10.1093/molbev/mst197 PMID: 24132122

44. Bandelt, H.J.; Forster P.; Rohl A.; Median-joining networks for inferring intraspecific phylogenies. Mol Biol Evol. 1999, 37-48. doi: pmid:10331250.

45. Louni, M.; Mana, N.; Bitam, I.; Dahmani, M.; Parola, P.; Fenollar, F.; Raoult. D.; Mediannikov, O. Body lice of homeless people reveal the presence of several emerging bacterial pathogens in northern Algeria. PLOS Neglected Tropical Diseases. 2018. 12, 4, e0006397. doi: org/10.1371/journal.pntd.000639

46. Rolain, J.-M.; Stuhl, L.; Maurin, M.; Raoult, D. Evaluation of Antibiotic Susceptibilities of Three Rickettsial Species Including Rickettsia felis by a Quantitative PCR DNA Assay. Antimicrob. Agents Chemother. 2002, 46, 2747-2751. doi:10.1128/AAC.46.9.2747-2751.2002.

47. Parola, P.; Diatta, G.; Socolovschi, C.; Mediannikov, O.; Tall, A.; Bassene, H.; Trape, J.F.; Raoult, D. Tick-Borne Relapsing Fever Borreliosis, Rural Senegal. Emerg. Infect. Dis. 2011, 17, 883-885. doi:10.3201/eid1705.100573. 
48. Raoult, D.; Angelakis, E.; Socolovschi, C. Bartonella quintana in Cimex hemipterus, Rwanda. Am. J. Trop. Med. Hyg. 2013, 89, 986-987. doi:10.4269/ajtmh.130182.

49. Mediannikov, O.; Fenollar, F.; Socolovschi, C.; Diatta, G.; Bassene, H.; Molez, J.-F.; Sokhna, C.; Trape, J.-F.; Raoult, D. Coxiella burnetii in Humans and Ticks in Rural Senegal. PLoS Negl. Trop. Dis. 2010, 4, e654. doi:10.1371/journal.pntd.0000654.

50. Dahmani, M.; Davoust, B.; Rousseau, F.; Raoult, D.; Fenollar, F.; Mediannikov, O.; Natural Anaplasmataceae infection in Rhipicephalus bursa ticks collected from sheep in the French Basque Country. Ticks Tick Borne Dis. Elsevier GmbH. 2017, 18-24. doi.org/10.1016/j.ttbdis.2016.09.009.

51. Bouvresse, S.; Socolovshi, C.; Berdjane, Z.; Durand. R.; Izri, A.; Raoult, D. et al. No evidence of Bartonella quintana but detection of Acinetobacter baumannii in head lice from elementary schoolchildren in Paris. Comp Immunol Microbiol Infect Dis. Elsevier Ltd. 2011; 34: 475-477. doi: .org/10.1016/j.cimid. 2011.08.007.

52. La Scola, B.; Gundi, V.A.K.B.; Khamis, A.; Raoult, D. Sequencing of the rроB Gene and Flanking Spacers for Molecular Identification of Acinetobacter Species. J. Clin. Microbiol. 2006, 44, 827-832, doi:10.1128/JCM.44.3.827-832.2006.

53. Ly, T.D.A.; Kerbaj, J.; Edouard, S.; Hoang, V.T.; Louni, M.; Dao, T.L.; Benkouiten, S.; Badiaga, S.; Tissot-Dupont, H.; Raoult, D.; et al. The Presence of Acinetobacter baumannii DNA on the skin of homeless people and its relationship with body lice infestation. Preliminary Results. Front. Cell. Infect. Microbiol. 2019, 9, 86, doi:10.3389/fcimb.2019.00086.

54. Kempf, M.; Rolain, J-M.; Diatta, G.; Azza, S.; Samb, B.; Mediannikov, O.; Sow, G.A.; Diene, S.M.; Fenollar, F.; Raoult, D. Carbapenem Resistance and Acinetobacter baumannii in Senegal: The Paradigm of a Common Phenomenon in Natural Reservoirs. PLoS ONE. 2012. 7, 6, e39495. doi: id=10.1371/journal.pone.0039495

55. La Scola, B.; Raoult, D. Acinetobacter baumannii in Human Body Louse. Emerg. Infect. Dis. 2004, 10, 1671-1673, doi:10.3201/eid1009.040242.

56. Huang, X.-Z.; Cash, D.M.; Chahine, M.A.; Nikolich, M.P.; Craft, D.W. Development and validation of a multiplex TaqMan real-time PCR for rapid detection of genes encoding four types of class D carbapenemase in Acinetobacter baumannii. J. Med. Microbiol. 2012, 61, 1532-1537, doi:10.1099/jmm.0.045823-0.

57. Xiong, H.; Campelo, D.; Boutellis, A.; Raoult, D.; Alem, M.; Ali, J.; et al. SNPs in entire mitochondrial genome sequences $(\approx 15.4 \mathrm{~kb})$ and coxl sequences $(\approx 486 \mathrm{bp})$ 
resolve body and head lice from doubly infected people from Ethiopia, China, Nepal, and Iran but not France. J Med Entomol. 2014, 51:1199-207. doi: 10.1603/ME14001

58. Liang, B.; ShaoCun, Z.; Yong, D.; ChengCheng, S., GuangBo, K.; Yan, D.; Yue, W.; Feng, G.; He, H.; Comparative genomics analysis of Acinetobacter haemolyticus isolates from sputum samples of respiratory patients. Genomics. 2020, 112, 4, 2784-2793. doi : pii/S0888754319308699. 